Article

\title{
Study on the Early Warning Methods of Dynamic Landslides of Large Abandoned Rockfill Slopes
}

\author{
Nan Qiao ${ }^{1, *}$, Yun-Ling Duan ${ }^{1}$, Xiao-Meng Shi ${ }^{2}$, Xue-Fei Wei ${ }^{3}$ and Jin-Ming Feng ${ }^{1}$ \\ 1 State Key Laboratory of Hydroscience and Engineering, Tsinghua University, Beijing 100084, China; \\ yduan@tsinghua.edu.cn (Y.-L.D.); jmfeng126@126.com (J.-M.F.) \\ 2 School of Civil Engineering, Beijing Jiaotong University, Beijing 100044, China; shixm@bjtu.edu.cn \\ 3 CIECC Engineering Company Limited, Beijing 100048, China; wxf0341@163.com \\ * Correspondence: qn13@mails.tsinghua.edu.cn
}

Received: 22 July 2020; Accepted: 28 August 2020; Published: 2 September 2020

\begin{abstract}
The excavation of large-scale underground projects produces a large amount of rubble waste material that is temporarily deposited near the project site, which forms a large-scale waste rockfill artificial slope. The slope has a granular structure, thus, during excavation and trans-shipment, surface shallow landslides may frequently occur. Existing contact monitoring methods such as buried sensors and GPS (Global Position System) are difficult to apply to the monitoring of rockfill landslides. Therefore, there are no appropriate early warning methods for waste rockfill slope landslides during dynamic transfer. Here, we used ground-based interferometric synthetic aperture radar to monitor the deformation of a rockfill slope during the excavation and transfer processes as a proposed method for the early warning against landslides on rockfill slopes during dynamic construction based on the radar interference measurement results. Through data cleaning and data interpolation, the line of equal displacement was generated, and the cross-sectional area of the equal displacement bodies of landslides was calculated. In addition, we established a four-level early warning grading standard, with the rate of change of the cross-sectional area of the equal displacement body as the early warning index, and realized real-time dynamic early warning of waste rockfill landslides during excavation and transportation. Finally, five landslide examples were used to verify the proposed warning method. The results show that the warning method can make an early warning $8-14$ min before the occurrence of landslide, which can effectively avoid the appearance of catastrophic events.
\end{abstract}

Keywords: rockfill; ground-based interferometric synthetic aperture radar; construction; cross-sectional area of equal displacement body; landslide warning method

\section{Introduction}

In recent years, the construction volume of large underground projects in China has grown [1]. During underground engineering excavation, a large amount of rubble waste material is temporarily piled up near the project area to form a large-scale waste rockfill body. With the development and utilization of rubble waste material, the temporary waste material dump needs to be excavated and transported. Excavation disturbance inevitably causes slope failure. Therefore, the safety of waste rockfill slopes during excavation and transportation has become an important factor [2].

Slope deformation monitoring and landslide warning rank high among the most effective safety prevention and control measures [3]. Displacement monitoring forms the basis of landslide deformation monitoring. Slope displacement and its related parameters are important reference indicators for landslide early warning research [4]. In 1968, Saito proposed the "three-segment" change rule of slope displacement-time curves [5]. Since then, scholars have conducted a vast amount of research on slope deformation monitoring and landslide warning from different perspectives and with different means. 
For instance, Hoek (1970) analyzed the displacement-time curve measured at the Chuquicanata mine and proposed an extension method to extrapolate the displacement-time curves and to predict the time of landslides according to the curve trend [6-8]. Zhong proposed the Verhulst inverse function model according to the characteristics of displacement-time curves [9]. Qiang et al. analyzed and studied many typical landslide displacement monitoring results and proposed a landslide early warning method using acceleration as the evaluation index [10]. In addition, many scholars have tried to combine various mathematical models with slope displacement-time curves. Such examples include the golden section method for early warning of the time of landslides [11-13], the markov early warning model $[14,15]$, the fuzzy mathematics early warning model $[16,17]$, the poisson cycle early warning model [18-21], and the gradient-sinusoidal early warning model [20,22,23].

For natural landslides, the displacement vectors at various points on the landslide body can generally be kept consistent. Even under special circumstances, the deformation of each point in the initial stage of slope deformation is disordered, but, once entering deformation acceleration, the displacement of each point on the landslide body and the time curve also tend to be the same. Therefore, the displacement data of one or more monitoring points can be used as the basis for slope deformation analysis and landslide warning research [24]. However, the waste rockfill are massive and unconsolidated and feature dynamic excavation and transportation processes. In slope deformation monitoring, it is difficult to apply contact monitoring methods such as embedded sensors and GPS. Because of the granular structure characteristics of a rockfill body, the rubble particles on the slope will rotate during slope excavation, which leads to inconsistent deformation among the rubble. It is irrational to describe the displacement and warn of the deformation of the slope by a single point. Therefore, traditional slope monitoring and landslide warning methods are not applicable for large abandoned rockfill slopes.

To effectively solve the problem of catastrophic events that may occur on the slopes of the rockfills, it is necessary to select appropriate monitoring methods, to describe the deformation process of slopes with scientific quantitative indicators, and to provide early warning for slope landslides. GB-InSAR (ground-based interferometric synthetic aperture radar) can provide full-field deformation information within the monitored area [25], which makes it possible to use the change of deformation region on the slope as the characteristic value to study the slope deformation. Therefore, the GB-InSAR system (IBIS-L system from Innovative Interferometric Radar for Environmental and Civil Engineering Applications, Italy) was used to carry out on-site monitoring tests on the slope of China's first temporary large-scale groundwater-sealed oil storage dumping site in Huangdao, Shandong Province. Through data processing of the full-field displacement results obtained from monitoring (data cleaning, data interpolation, generating equal displacement lines, etc.), we propose to describe the deformation process of the slope by using the curve of the cross-sectional area of the constant displacement body with time. By summarizing the results of the data, a landslide early warning method with an equal displacement cross-sectional area as an early warning index is proposed to achieve the real-time monitoring and early warning of rockfill landslides during construction.

\section{Project Overview}

The waste rockfill is located about $500 \mathrm{~m}$ southwest of the underground project entrance, and the floor area is approximately $9.6 \times 10^{4} \mathrm{~m}^{2}$. The ground where the waste rockfill body is located is high in the north and low in the south, and the difference of elevation between the south and north is about $20 \mathrm{~m}$. The east and west directions are relatively gentle, and there is a slightly protruding depression in the middle part. The difference of elevation is about $4 \mathrm{~m}$. The waste rockfill is dumped by a dump truck [26], and it is leveled by a bulldozer. The rockfill body slopes can be divided into two stages based on the formation process. The boundary between the two stages are shown in Figure 1 (the yellow dotted line). 


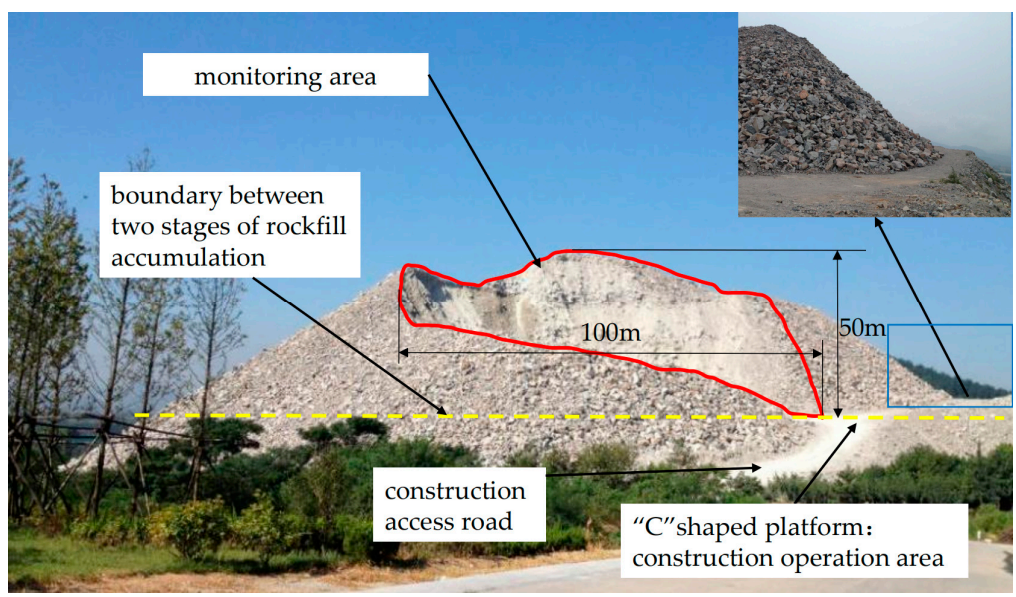

Figure 1. Overview of the rockfill. The horizontal boundary width of the red curve is about $100 \mathrm{~m}$, and the maximum vertical level difference is about $50 \mathrm{~m}$.

The waste is mainly rubble produced by the blasting and crushing of granite gneiss. Table 1 shows the petrophysical and mechanical properties of granite gneiss in intact rock mass. The rockfill is highly porous and unconsolidated with high permeability of the rubble. The bottom of the rockfill body is composed of large rubbles with an average particle size of $1 \mathrm{~m}$, and the rubble particles are independent of each other. The slope within the monitoring area (the red polygon area in Figure 1) is the residual slope after the occurrence of the previous landslides, and many large boulders are already broken, having an average size of 10-50 cm (Figure 2). Besides, due to the occurrence of landslide, the rock rolling and impact will be broken, resulting in much coarse-grained soil left on the slope.

Table 1. Physical and mechanical properties of intact rocks (from geological survey report).

\begin{tabular}{|c|c|c|c|c|c|c|}
\hline \multirow[b]{2}{*}{ Classification } & \multirow[b]{2}{*}{$\begin{array}{l}\text { Specific } \\
\text { Gravity }\end{array}$} & \multirow[b]{2}{*}{$\begin{array}{l}\text { Uniaxial Saturation } \\
\text { Compressive } \\
\text { Strength (MPa) }\end{array}$} & \multirow[b]{2}{*}{$\begin{array}{c}\text { Elasticity } \\
\text { Modulus (GPa) }\end{array}$} & \multicolumn{2}{|c|}{ Shearing Strength } & \multirow[b]{2}{*}{$\begin{array}{c}\text { Tensile } \\
\text { Strength (MPa) }\end{array}$} \\
\hline & & & & Cohesion (MPa) & $\begin{array}{l}\text { Internal } \\
\text { Friction } \\
\text { Angle }\left(^{\circ}\right)\end{array}$ & \\
\hline $\begin{array}{l}\text { Granite gneiss } \\
\text { below }+20 \mathrm{~m} \\
\text { (the elevation of } \\
\text { the underground } \\
\text { cavern roof is } \\
-30 \mathrm{~m} \text { ) }\end{array}$ & 2.6 & 90.7 & 52.7 & 10.2 & 71.1 & 11.7 \\
\hline
\end{tabular}

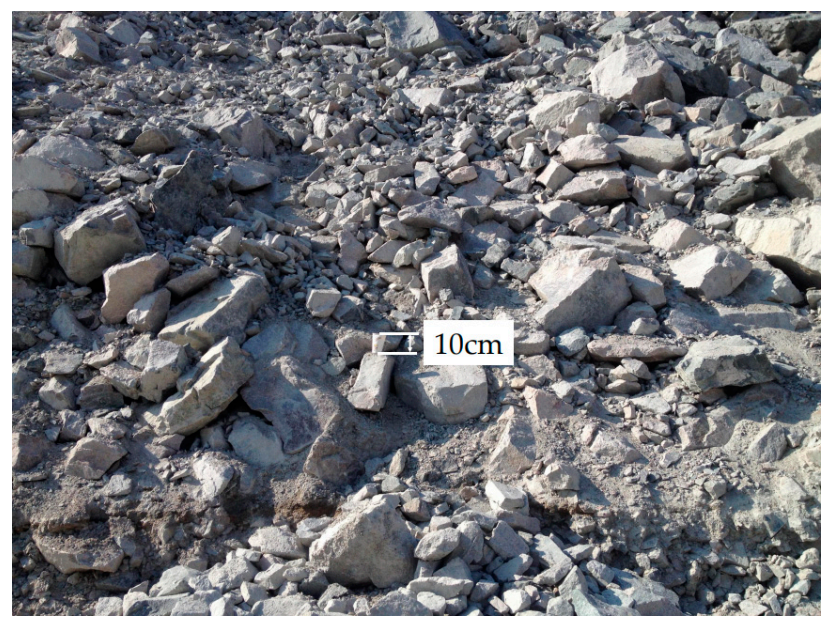

Figure 2. Rock fragments left on the slope after the previous landslide. 
Due to the stacking height limits and the economic value of rubble, rubble waste is transferred to a dumping site about $1 \mathrm{~km}$ south of the site of rubble transfer, as shown in Figure 3.

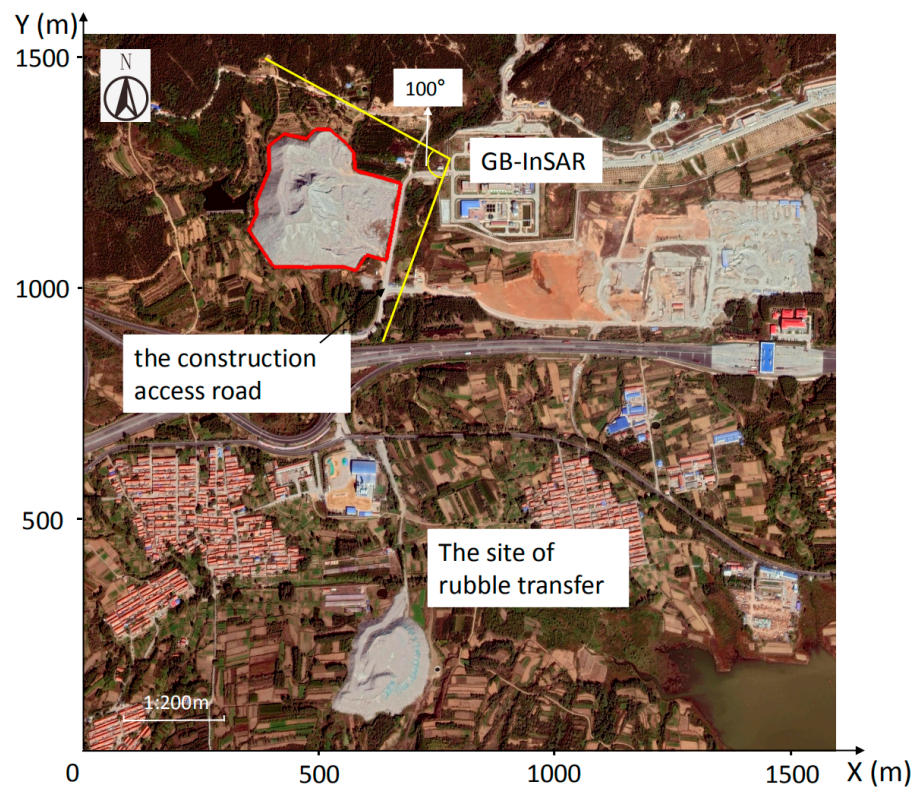

Figure 3. Relative position of project site (adapted from google maps). Where GB-InSAR is ground-based interferometric synthetic aperture radar.

To prevent uncontrollable large-scale slippage caused by an excavation-related disturbance, rubble excavation is carried out in two phases. In the first phase, a " $\mathrm{C}$ "-shaped platform is constructed above the platform of the original rockfill body. Excavation is carried out using construction equipment located on the platform (Figure 4) to control the location and slope height of the area affected by the excavation, thereby controlling the scale of the landslide and the direction of the sliding body. After the removal of most of the rubble via the above the platform, the second phase of the operation is to transport the rubble under the platform.

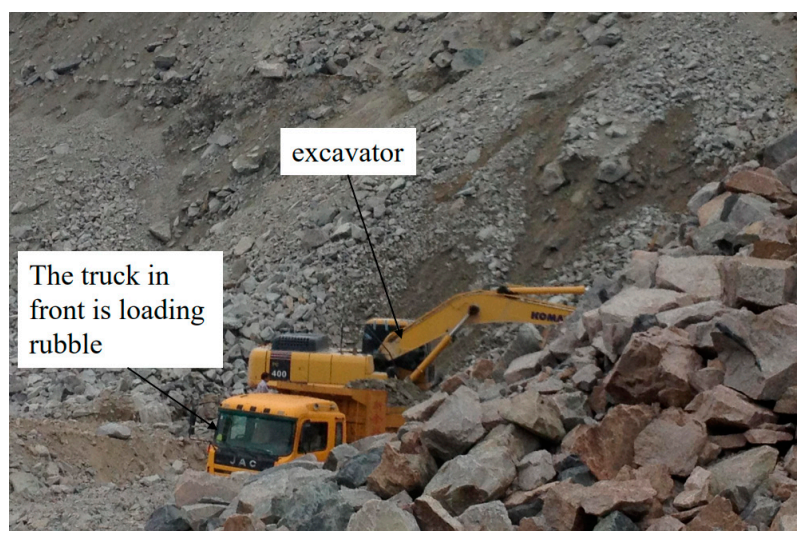

Figure 4. Loading and transportation.

\section{Slope Monitoring of Large-Scale Abandoned Rockfill Based on Ground-Based Interferometric Synthetic Aperture Radar}

\subsection{Monitoring Equipment}

This research used the IBIS-L system [2,27] for monitoring. The IBIS-L system is mainly composed of four parts: radar sensor, linear scanner, computer, and power supply module (Figure 5). When using 
IBIS for field monitoring tests, in addition to ensuring the normal monitoring of the target, the power supply of the equipment should also be considered. IBIS has a power of about $100 \mathrm{~W}$. Even though a battery can be used as a power source, it does not effectively guarantee the continuous working time of IBIS.

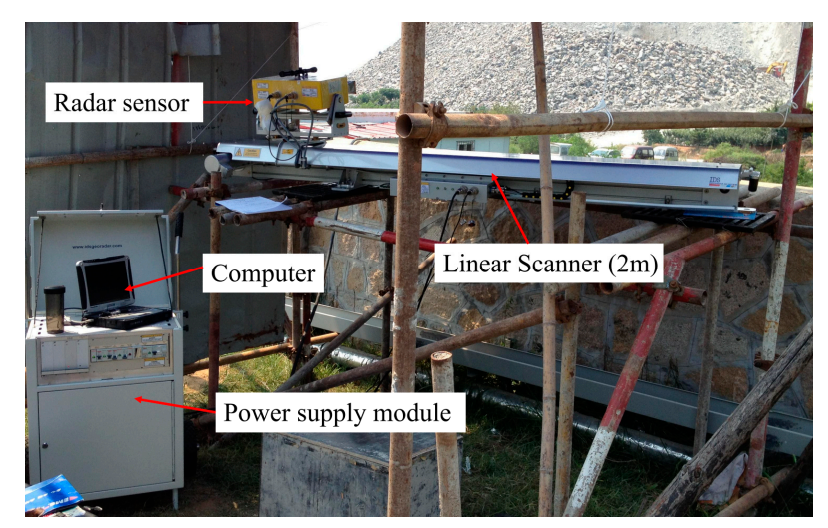

Figure 5. IBIS-L system (from Innovative Interferometric Radar for Environmental and Civil Engineering Applications, Italy) composition.

The theoretical monitoring range of the IBIS-L system is $0-4000 \mathrm{~m}$. Due to the limitation of the radar antenna beam angle, the azimuth monitoring range is $-50^{\circ}$ to $50^{\circ}$. The specific system parameter settings are shown in Table 2. As for the working process of the system, the computer controls the radar sensor to move from the left end to the right end of the linear guide in an "off-on-off" manner. The length of the linear guide is $2 \mathrm{~m}$, "off" every $5 \mathrm{~mm}$, during which electromagnetic waves are emitted and echoes are received a total of 401 times. Then, the received signal is processed by synthetic aperture technology to realize azimuth focusing. Finally, according to the phase information of each pixel obtained by the synthetic aperture, the deformation information $d$ of the target can be acquired by the interferometry of the phase difference between the echo signals of the targets at different times:

$$
d=\frac{\lambda\left(\varphi_{2}-\varphi_{1}\right)}{4 \pi}
$$

where $\varphi_{1}$ and $\varphi_{2}$ represent the phase information of each pixel obtained by synthetic aperture at different times, and $\lambda$ is the radar wavelength. Thus, the displacement of each pixel in the whole field can be obtained.

Table 2. The parameters of IBIS-L.

\begin{tabular}{cc}
\multicolumn{2}{c}{ System Parameters } \\
\hline Range resolution (the range of the minimum resolution element) \\
Azimuth resolution & $0.5 \mathrm{~m}$ \\
Accuracy & $4.4 \mathrm{mrad}$ \\
Operating range & $0.1 \mathrm{~mm}$ \\
Frequency band & $10-4000 \mathrm{~m}$ \\
Scan time & $17.1-17.3 \mathrm{GHz}$ \\
Linear scansion length & $5 \mathrm{~min}$ \\
Power consumption & $2 \mathrm{~m}$ \\
\hline
\end{tabular}

\subsection{Monitoring Plan}

To make a preliminary judgment on the position of the site excavation and potential landslides, the optimal monitoring angle of GB-InSAR was first ensured, and, at the same time, the safety of the equipment and the power supply requirements were taken into account. The GB-InSAR was located at the project department entrance about $120 \mathrm{~m}$ to the northeast of the rockfill, as shown in 
Figure 2. The range indicated by the red line in the figure is the area occupied by the piled rockfill, and the range indicated by the yellow line is the azimuth scanning range of the radar.

\subsection{Monitoring Results}

The monitoring lasted 69 days, during which time 11,376 observations were obtained and 72 shallow landslides (the sliding surface depth did not exceed $1 \mathrm{~m}$ ) were recorded, including 41 small-area landslides that were destroyed within a short time by excavator disturbance. However, when the tops of some slopes were removed, it made it very easy to lose control, resulting in large-scale landslides. In total, 31 larger landslides were recorded, as shown in Figure 6, where the top of the slopes was removed. The records of the landslide area of the 72 landslides are shown in Figure 7, and the numbers represent the landslide areas, where the landslide area is the area of each landslide which was recorded during the field monitoring. The source of the final landslide area record was divided into two parts. Firstly, all the landslide area records that occurred during the day were recorded from the perspective of radar through visual estimation. Secondly, almost all the records of the landslide area from night to morning were obtained by the visual estimation of the construction workers standing near the bottom of the slope. Then, the landslide area visible to the radar could be calculated according to the relative position of the radar position, the construction personnel, and the landslide position. However, the landslide area records shown in this paper are estimated values of the landslide area from the perspective of radar. The landslide areas shown in Figure 7 are the final data that could be measured by radar.

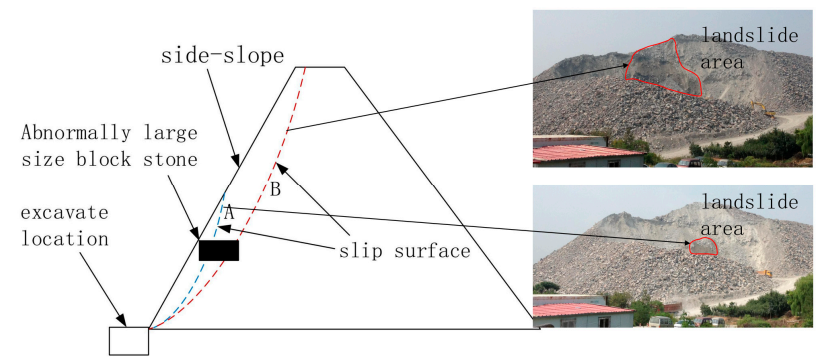

Figure 6. Position of the sliding surface. The 72 landslides records can be divided into two types according to the position of the sliding surface as A and B. Examples of the two types of landslide surfaces are shown on the right.

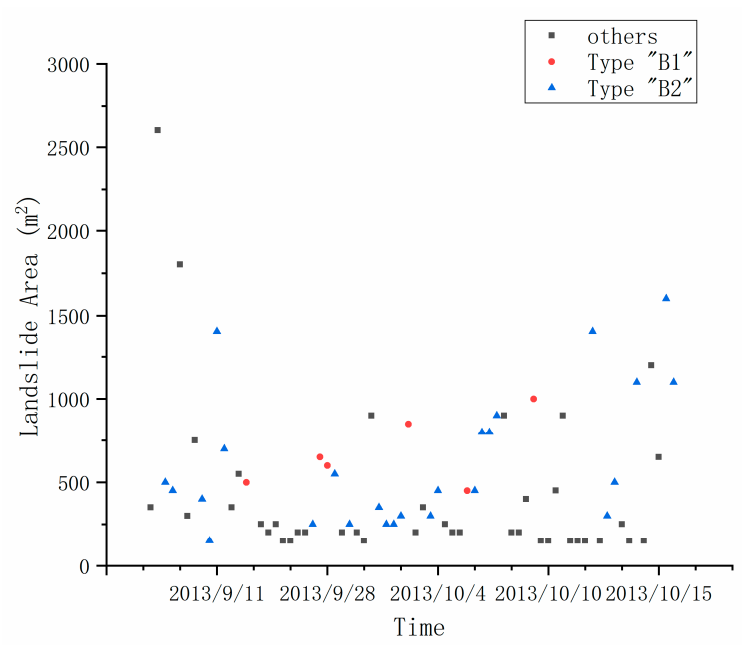

Figure 7. Landslide areas (72 landslides). The landslide area is the area of each landslide recorded during the field monitoring. These data are not accurate measurements but intuitive estimates. Since this paper is based on IBIS-L measurement results for analysis, the area data in the figure represent the area of the landslide area that can be seen by the corresponding radar equipment. 
According to the field observation, the surface morphology of the 31 landslides can be divided into two types. One is the slope surface above the excavation location of the mechanical equipment, which has no apparent large particle size and dense agglomeration zone. The other is the slope with a significant dense zone (Figure 8). Due to rainfall, the rolling of construction vehicles, and the uneven particle sizes, some layers or areas of the rockfill have a higher density than the surrounding dense zone. Therefore, the 31 landslides were classified based on the surface shape of the slopes (Table 3).

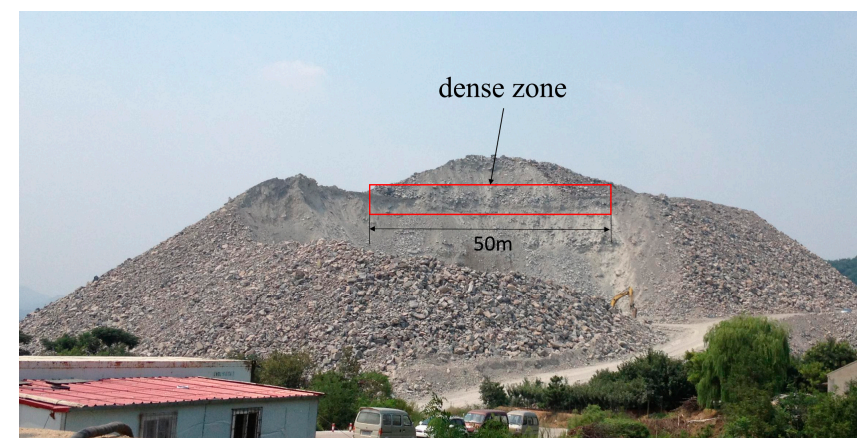

Figure 8. Slope with a significant dense zone.

Table 3. Classification of landslides.

\begin{tabular}{ccc}
\hline Landslide Classification & Classification Basis & Number of Landslides \\
\hline Type "B1" & There is a dense belt, the slope surface is uneven. & 6 \\
Type "B2" & No dense belt, the slope surface is even. & 25 \\
\hline
\end{tabular}

This article focuses on the abovementioned 31 landslides. First, according to the monitoring results of IBIS-L, the echo signals of each pixel were extracted. Then, we dealt with the pixels that could not meet the precision requirement. The displacement values of the remaining pixels in each monitoring period were calculated by Equation (1). According to the displacement values of existing pixel points, the interpolation method could obtain the displacement values of all pixel points in the area around each cleaned point. Finally, the contour of equal displacement could be generated based on the values. Considering the limitation of displacement monitoring accuracy of IBIS-L, the displacement cross-sectional area of $-0.5 \mathrm{~mm}$ was selected as the index for the landslide early warning research. The $-0.5 \mathrm{~mm}$ equal displacement cross-sectional areas of 31 landslides at different times were extracted, as shown in Figure 9.

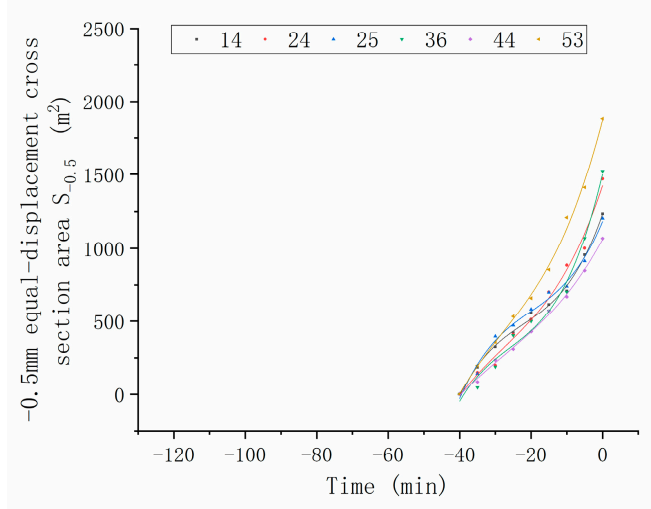

(a) Type "B1"

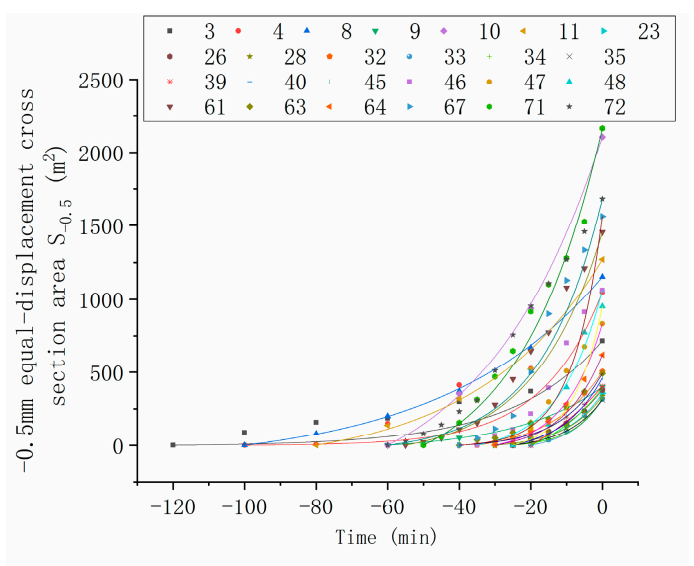

(b) Type "B2"

Figure 9. The area-time curve of the equal displacement cross section. The numbers in the legend represent landslide numbers recorded in chronological order. The " 0 " time represents the last scan before the severe landslides. 
The two types of different slope forms exhibit two distinct curves under the same excavation construction conditions. The $-0.5 \mathrm{~mm}$ equal displacement cross-sectional area of a Type B1 landslide lasts about $30-40 \mathrm{~min}$ before a landslide, and it is a cubic curve. The reason for this is the dense zone on the slope has a significant supporting effect on the upper rubble during the deformation of the slope. The $-0.5 \mathrm{~mm}$ equal displacement cross-sectional area of a Type B2 landslide varies with time for about 30-120 $\mathrm{min}$, and most last less than $60 \mathrm{~min}$. The curve conforms to the exponential form with the accelerated deformation stage in the three sections of the slope displacement-time curve.

\section{Early Warning Method for Landslides Based on the Rate of Change of the Cross-Sectional Area of Equal Displacement Bodies}

The uniqueness of waste rockfill bodies makes it unsuitable to use single-point displacement as an indicator for slope deformation analysis or empirical judgment. Therefore, in this study, the deformation characteristics of waste rockfill slopes were characterized by the change of the cross-sectional area of the equal displacement body. On this basis, a warning method for waste rockfill slope landslides during excavation is proposed.

\subsection{Ideas on Early Warning}

(1A) Based on the results in [2] and the 26 landslides monitored in the previous period (the remaining five landslides were used to verify the early warning method), the surface characteristics of waste rockfill slopes can be identified, and a preliminary judgment can be made about the possible landslide patterns in the excavation process. During the accumulation of waste rockfill, the density of some accumulation layers and areas caused by rainfall, the rolling of construction vehicles, etc. is quite different, or there might be a certain amount of abnormally large-sized rubble on the slope surface and in the shallow layer. Both conditions play a great role in supporting the rubble particles above the dense zone. Therefore, combined with the surface characteristics of the rockfill slope, a possible landslide pattern can be determined through the analysis of the characteristics of the cross-sectional area of different displacement bodies over time.

(1B) For possible landslides being monitored, based on the real-time constant displacement cross-sectional area data obtained from slope deformation monitoring, a time series prediction model such as ARIMA-SVR [28] (Autoregressive Integrated Moving Average model-Support Vector Regression: a hybrid ARIMA and SVR model of time series prediction mode) can be used. Based on the existing data and the prediction of future data, the future trend of constant displacement cross-sectional areas can be predicted.

(2) Real-time monitoring data can be extracted, the real-time changing process of the cross-sectional area of equal displacement can be studied and analyzed, and the mode of slope deformation can be determined according to the change trend of the cross-sectional area of the equal displacement body.

(3) According to the measured $(1 \mathrm{~A})$ and predicted values of the cross-sectional area of the equal displacement body (1B), the relationship between the cross-sectional area change of the equal displacement body in different modes and landslides of the rockfill slope can be analyzed, and an early warning judgment of such landslides can be determined. Then, the change process of the cross-sectional area of different landslides and equal displacement bodies can be independently analyzed.

(4) On the basis of the determined early warning criteria of the rockfill slope, an early warning grade division standard of the rockfill slope can be established.

The detailed process is shown in Figure 10. 


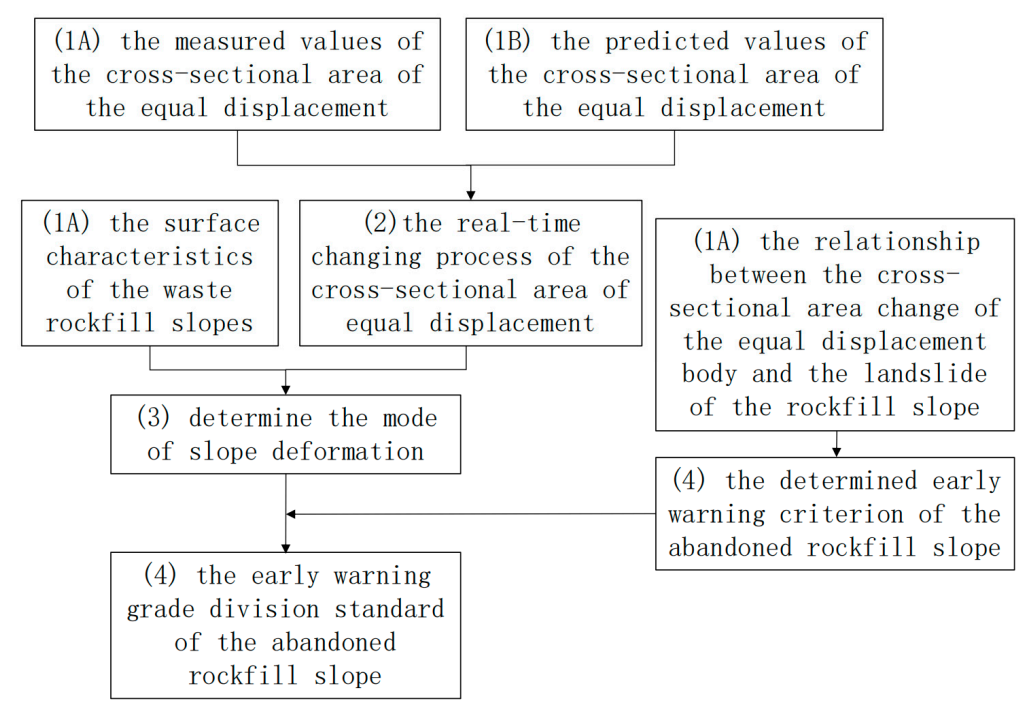

Figure 10. Early warning method of landslides.

\subsection{Early Warning Indicators and Grading Standard}

Considering the needs of on-site early warning in terms of the number of data calculations and the data extraction speed, under the condition of ensuring the accuracy of radar displacement monitoring, the deformation of $-0.5 \mathrm{~mm}$ on the slope is easier to identify in time. Therefore, the cross-sectional area of the $-0.5 \mathrm{~mm}$ equal displacement body was used as an index to validate the early warning method of the rockfill slope during excavation and transportation [2]. The on-site conditions of waste rockfill slope landslides are complicated, and both different and similar types of landslides often occur in the same area. Therefore, the cross-sectional area of the $-0.5 \mathrm{~mm}$ equal displacement body was normalized, and then the rate of change was used as a warning indicator of landslides. The cross-sectional area of the $-0.5 \mathrm{~mm}$ constant displacement body at each moment after normalization is

$$
S_{-0.5}^{*}(t)=\frac{S_{-0.5}(t)}{S_{\max }}
$$

where $S_{-0.5}(t)$ is the measured or predicted value of the cross-sectional area of the $-0.5 \mathrm{~mm}$ constant displacement body at time $t$ and $\mathrm{S}_{\max }$ is the cumulative value of the cross-sectional area of the $-0.5 \mathrm{~mm}$ equal displacement body obtained from the last measurement before the slope starts sliding.

The normalized $-0.5 \mathrm{~mm}$ equal displacement body cross-sectional area change rate is

$$
V_{-0.5}^{*}(t)=\frac{S_{-0.5}(t)^{\prime}}{S_{\max }}
$$

Based on the field measurement results and the analogy between landslide cases, the characteristics of the cross-sectional area of the $-0.5 \mathrm{~mm}$ equal displacement body of the two types of 29 landslides that were previously monitored in the rockfill were statistically analyzed. Then, early warning standards were developed according to two different types of landslides. Since the data selected were actually measured landslide data, the lower limit of the $95 \%$ confidence band of the mean value of the cross-sectional area of the two types of landslides of the $-0.5 \mathrm{~mm}$ equal displacement body was selected as the standard to formulate the landslide warning level. According to the characteristic values of $50 \%, 30 \%$, and $10 \%$ of the lower limit of the $95 \%$ confidence band of the average displacement rate of the cross-sectional area of the $-0.5 \mathrm{~mm}$ equal displacement body before sliding, the landslide warning was divided into five levels, as shown in Figure 6. Note that the rate of change of the cross-sectional area of the "B1"-type landslide of the $-0.5 \mathrm{~mm}$ equal displacement body shows a decreasing trend within a certain period of the initial stage of the development of the displacement field. Therefore, 
the maximum value of $V_{-0.5}^{*}(t)$ before the start of deformation acceleration is defined as the upper limit of the yellow warning for class B landslides. To make the early warning method more convenient and to ensure the compatibility of the two types of landslides, the early warning standard was uniformly divided into four levels based on the statistical results of the early warning thresholds of the two types of landslides, as shown in Figure 11. The grading results and construction regulations were then established, as shown in Table 4.

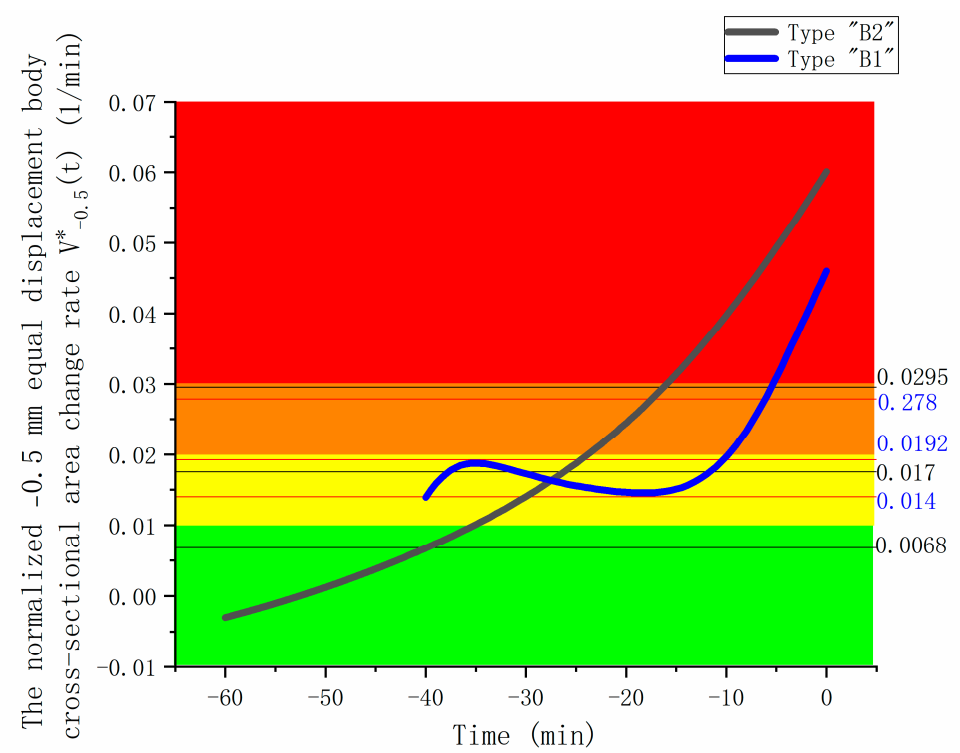

Figure 11. The lower limit of the $95 \%$ confidence band for $V_{-0.5}^{*}(t)$

Table 4. Early warning classification and dynamic control method of the waste rockfill slope during excavation and transportation.

\begin{tabular}{ccccc}
\hline Warning Level & Level 1 & Level 2 & Level 3 & Level 4 \\
\cline { 2 - 5 } Early-warning Index & Green & Yellow & Orange & Red \\
\hline Slope Status & Stable & Relatively Stable & Relatively Unstable & Unstable \\
\hline Evaluation & $<0.01$ & $0.01-0.02$ & $0.02-0.03$ & $\geq 0.03$ \\
\hline Dynamic regulation & Stable & Relatively stable & Relatively dangerous & Dangerous \\
\hline Construct as normal & Construct as & $\begin{array}{c}\text { Pay close attention to } \\
\text { normal while } \\
\text { the slope anomalies } \\
\text { and adjust } \\
\text { pang attention to } \\
\text { the slopes }\end{array}$ & $\begin{array}{c}\text { Stop construction } \\
\text { immediately } \\
\text { and evacuate, } \\
\text { evacuate the original } \\
\text { position appropriately } \\
\text { excavation location, } \\
\text { and avoid landslides }\end{array}$ \\
\hline
\end{tabular}

\section{Method Validation}

To check the feasibility and reliability of the landslide warning method of rockfill slopes, the last five landslides of two different types of landslides recorded during field monitoring were used to verify the landslide warning method.

The waste rockfill slope was taken as the remaining broken surface after the previous landslide, and the slope angle was approximately $35-38^{\circ}$. The excavation and loading speed during construction was approximately a 10-t load muck truck loaded every 6-9 $\mathrm{min}$. During the five landslide monitoring periods, there was no rainfall, the daytime temperature was about $20-25{ }^{\circ} \mathrm{C}$, and the nighttime temperature was about $15-20^{\circ} \mathrm{C}$.

The landslides occurred at 4:55 on 5 October 2013, 2:45 on 10 October 2013, 3:00 on 15 October 2013, 21:00 on 15 October 2013, and 9:38 on 16 October 2013. The final landslide areas were 450, 1000, 1100, 1600 , and $1100 \mathrm{~m}^{2}$, respectively. The specific records are shown in Table 5 . 
Table 5. Characteristics of the five test landslides.

\begin{tabular}{ccccc}
\hline $\begin{array}{c}\text { Landslide } \\
\text { Number }\end{array}$ & $\begin{array}{c}\text { Types of Slopes } \\
\text { and Landslides }\end{array}$ & $\begin{array}{c}\text { Duration of } \\
\text { Displacement } \\
\text { to Failure }\end{array}$ & Moment of Landslide & Final Landslide Area \\
\hline Landslide 44 & Type “B1" & $40 \mathrm{~min}$ & 5 October 2013 4:55 & $450 \mathrm{~m}^{2}$ \\
Landslide 53 & Type "B1" & $40 \mathrm{~min}$ & 10 October 2013 2:45 & $1000 \mathrm{~m}^{2}$ \\
Landslide 67 & Type "B2" & $40 \mathrm{~min}$ & 15 October 2013 3:00 & $1100 \mathrm{~m}^{2}$ \\
Landslide 71 & Type "B2" & $50 \mathrm{~min}$ & 15 October 2013 21:00 & $1600 \mathrm{~m}^{2}$ \\
Landslide 72 & Type "B2" & $60 \mathrm{~min}$ & 16 October 2013 9:38 & $1100 \mathrm{~m}^{2}$ \\
\hline
\end{tabular}

First, the slope was initially classified according to whether there was a dense belt formed by the rolling of the slope or whether there was abnormally large-sized rubble in the middle of the slope. Landslides 44 and 53 conformed to the B1-type failure mode, while Landslides 67, 71, and 72 conformed to the B2-type failure mode. Then, ARIMA-SVR model was used to predict the variation trend of $-0.5 \mathrm{~mm}$ equal displacement cross-section area of these five landslides, and the results are shown in Figure 12. The average deviations between the predicted value and the measured value of five test landslides are shown in Table 6.

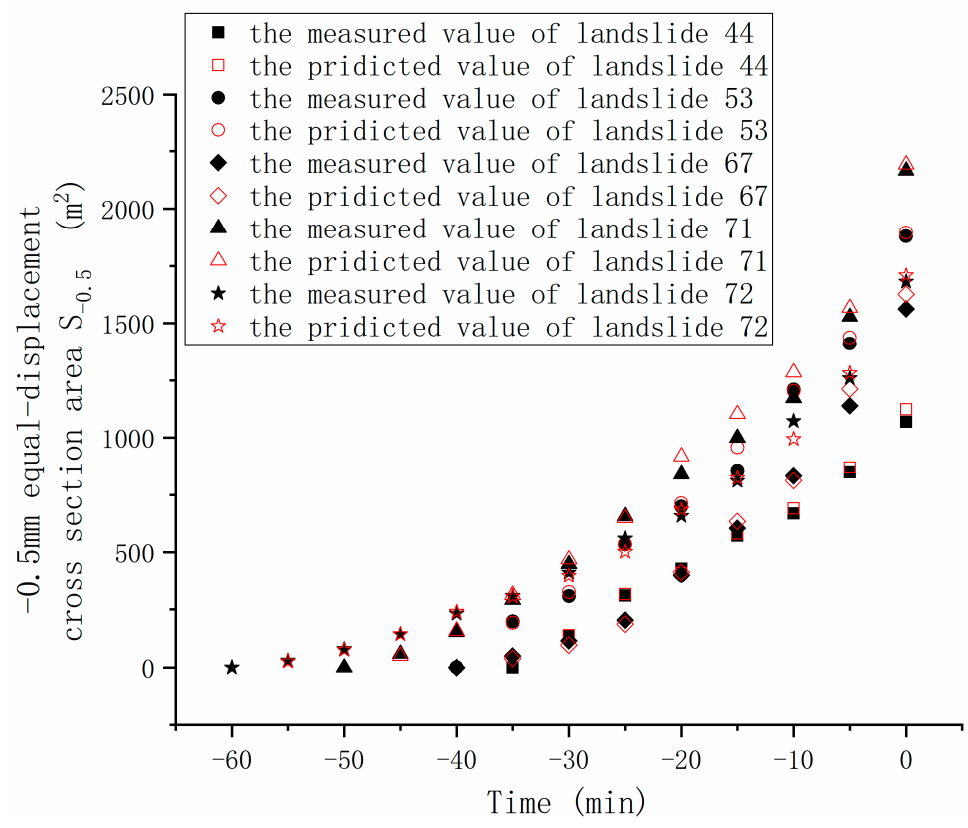

Figure 12. The measured and predicted values of the cross-sectional area of the $-0.5 \mathrm{~mm}$ equal displacement bodies.

Table 6. The average deviations between the predicted value and the measured value of the five test landslides.

\begin{tabular}{cccccc}
\hline Landslide Number & Landslide 44 & Landslide 53 & Landslide 67 & Landslide 71 & Landslide 72 \\
\hline Average deviations $\left(\mathrm{m}^{2}\right)$ & 9.8 & 11.9 & 15.3 & 21.2 & 10.5 \\
\hline
\end{tabular}

According to Equation (2), the prediction results of five $-0.5 \mathrm{~mm}$ equal displacement bodies of five landslides were normalized. Then, the deformation rates of the cross-sectional area of the $-0.5 \mathrm{~mm}$ equal displacement bodies were calculated after normalization using Equation (3). The results are shown in Figure 13. 


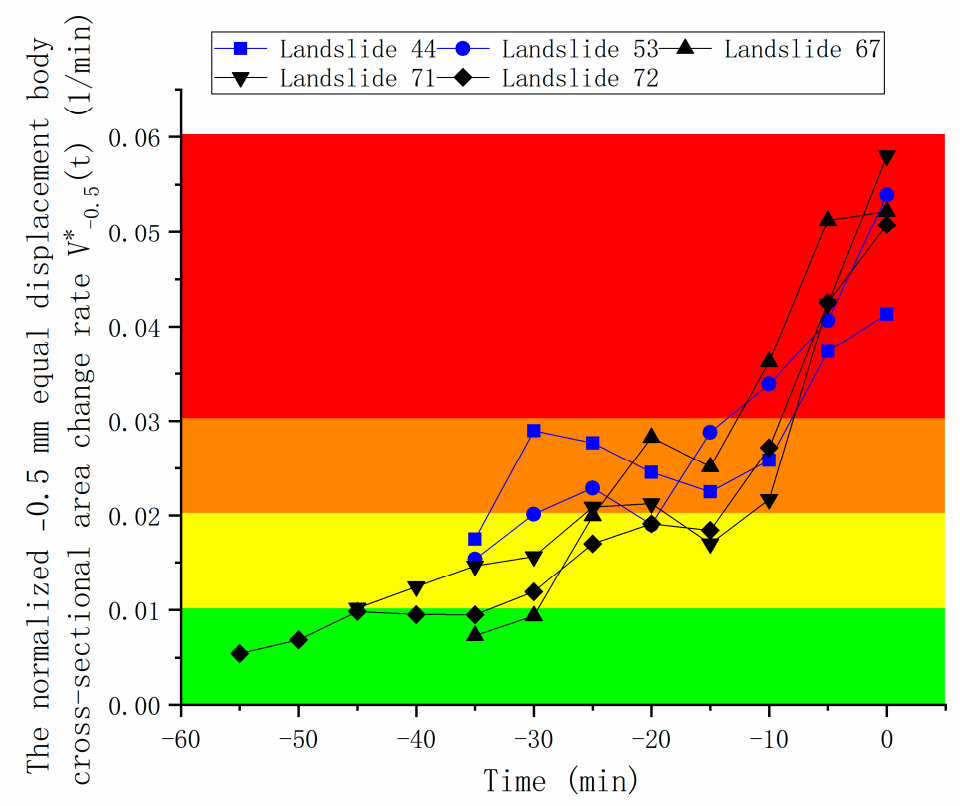

Figure 13. The normalized $-0.5 \mathrm{~mm}$ equal displacement body cross-sectional area change rate.

From the analysis results of the above examples, the landslide early warning method and the early warning classification established in this paper could provide a warning to avoid risks before the occurrence of all five tested landslides.

Compared with the traditional landslide warning method based on slope deformation, it mainly depends on the displacement of some points on the slope. For a loose rockfill slope, it is feasible to express the deformation of the slope by the displacement of a certain point, but it is difficult to find a suitable point. However, as described in Section 3.3, the variation curve of a $-0.5 \mathrm{~mm}$ equal displacement cross-sectional area over time conforms to the form of a "three-section" curve. Combined with previous research experience, this will make it easier for the equal displacement cross-sectional area to be used as an early warning indicator.

It should be noted that this verification was based on the last instance of landslide of each type on the site, and the actual working conditions were similar to the previous landslides. The establishment of the landslide warning standard also depends on the statistical results of these previous similar landslide cases. Therefore, these four successful landslide warnings are limited by certain working conditions, such as rock lithology, rubble particle gradation, rolling of vehicles during the accumulation of rock mass, rainfall, and so on. These conditions will directly affect the repose angle of the rockfill, and the repose angle is an important factor affecting rockfill landslides. Generally, when the angle of the slope is less than the repose angle, the slope is unstable. Rainfall has a direct impact on the water content of rockfill, which is directly proportional to the angle of internal friction. For loose rockfill, due to the structural characteristics of the large pores, leakage and evaporation are rapid, so water content is usually small. Particle gradation will also directly affect the repose angle of the rockfill body. Small-particle-size rubble plays a particular "lubrication" role in the rockfill body. When the content of small-particle-size rubble is relatively low, large-particle-size rubble relies on friction and the "aggregate interlock capacity of rubble" to keep the slope in a stable state. When the content of small-particle-size rubble is high, due to the "lubricating" effect of small-particle-size rubble particles, the relative movement between large-particle-size rubble particles is more likely to occur, resulting in slope instability. Therefore, for the slopes of other rockfill bodies under similar working conditions, the actual situation should be considered to make appropriate adjustments to the early warning standard. 
In general, most landslide warning models are based on the displacement-time curve of a single point on the slope. According to the curve change that conforms to the three stages of "initial deformation-uniform deformation-accelerated deformation", the landslide warning levels are divided into "caution-vigilance-danger". For example, Wang [29], He [30], and Qiang [31], among others, all studied the landslide early warning index and landslide early warning classification standard based on the "three stages" of the single point displacement-time curve. However, which point of displacement data should be selected as the basis in the process of landslide warning is a fundamental question. To solve this problem, Qiang [24] proposed that the deformation of each point on the slope is disordered before the basic penetration of the sliding surface. However, after the basic penetration of the sliding surface, the slope begins to slide as a whole. As mentioned above, the rockfill body is loosely piled, and the deformation of adjacent positions on the slope is disordered before the occurrence of landslide. Moreover, under the condition of excavation disturbance, a shallow landslide is likely to occur in a short time, and the time between the connection of the sliding surface and the occurrence of landslide is generally quick. The landslide early warning method established in this paper describes the deformation process of the slope through the area of equal displacement cross-section, avoiding the problem of selecting appropriate points on the slope, which has significant importance for landslide warning of loose accumulation.

\section{Conclusions}

Due to the granular structure of waste rockfills, it is difficult to find a suitable single-point displacement as an early warning index. The advantage of GB-InSAR full-field scanning is that it helps to obtain slope displacement and other displacement information (the electromagnetic wave reflection intensity of the measured target, etc.) through data processing. In this paper, a landslide early warning system based on the rate of change of the cross-sectional area of equal displacement bodies was proposed for the landslides of unconsolidated coarse sedimentary rocks.

By summarizing the previous landslide monitoring and data processing results, using the normalized rate of change of the cross-sectional area of a $-0.5 \mathrm{~mm}$ equal displacement body as the early warning criteria, two types of landslides and four levels of early warning classifications were established as follows: (a) Level 1 (green) warning area, $V_{-0.5}^{*}(t)<0.01$; (b) Level 2 (yellow) warning area, $0.01 \leq V_{-0.5}^{*}(t)<0.02$; (c) Level 3 (orange) warning area, $0.02 \leq V_{-0.5}^{*}(t)<0.03$; and (d) Level 4 (red) warning area, $V_{-0.5}^{*}(t) \geq 0.03$.

The validity of the early warning method was verified based on five landslides to compare the predicted and real values in this paper. Further research is needed to take into consideration comprehensive factors such as rock mechanics and rainfall for early warning of rockfill landslides.

Author Contributions: N.Q. contributed to conceptualization, numerical and experimental investigations, and preparation of the paper; Y.-L.D. contributed to conceptualization, numerical and experimental studies, and preparation of the paper; X.-M.S. contributed to conceptualization, numerical and experimental investigations, and preparation of the paper; X.-F.W. contributed to conceptualization, numerical and experimental investigations, and preparation of the paper; and J.-M.F. contributed to experimental investigations. All authors have read and agreed to the published version of the manuscript.

Funding: This research received no external funding.

Conflicts of Interest: The authors declare no conflict of interest.

\section{References}

1. Kairong, H. State of art and Prospect of Tunnels and Underground Works in China. Tunn. Constr. 2015, 35, 95.

2. Qiao, N.; Duan, Y.; Wei, X.; Shi, X. Study on Landslide Monitoring Experiment of Underground Chambers Spoil Area. EEES 2020, 455, 012212.

3. Chae, B.G.; Park, H.J.; Catani, F.; Simoni, A.; Berti, M. Landslide prediction, monitoring and early warning: A concise review of state-of-the-art. Geosci. J. 2017, 21, 1033-1070. [CrossRef]

4. Xu, F.; Wang, Y.; Du, J.; Ye, J. Study of displacement prediction model of landslide based on time series analysis. Chin. J. Rock Mech. Eng. 2011, 30, 746-751. 
5. Saito, M. Forecasting the time of occurrence of a slope failure. In Proceedings of the 6th International Conference on Soil Mechanics and Foundation Engineering, Montreal, QC, Canada, 8-15 September 1965; pp. 537-541.

6. Hoek, E. Estimating the stability of excavated slopes in opencast mines. Inst. Min. Metall. A 1970, 105, A132.

7. Hencher, S.R.; Liao, Q.H.; Monaghan, B.G. Modelling slope behaviour for open-pits. Trans. Inst. Min. Metall. Sect. A Min. Ind. 1996, 105, A37.

8. Faquan, W.; Niansheng, W. An Embryo of Dynamical Analysis Method on Landslide Displacement. Chin. J. Geol. Hazard. Control. 1996, 7, 38-41.

9. Zhong, Z.; Baochen LI, U. Verhulst Inverse-Function Residual Correction Model for Landslide Prediction and Forecast. China Railw. Sci. 2009, 4, 28-36.

10. Xu, Q.; Huang, R.Q.; Li, X.Z. Research progress in time forecast and prediction of landslides. Adv. Earth Sci. 2004, 3, 479-483.

11. Shitian, W.; Zhuoyuan, Z.; Zheng, Z. On the characteristics and dynamics of the catastrophic mount sale landslide, Gansu (kansu), China. J. Chengdu Univ. Technol. 1988, 2, 58-63.

12. Iading, W.; Zhuoyuan, Z. A study on the mechanism of high-speed loess landslide induced by earthquake. Chin. J. Geotech. Eng. Chin. Ed. 1999, 21, 670-674.

13. Siqing, Q. The nonlinear dynamics method to forecast landslide disaters. Hydrogeol. Eng. Geol. 1993, 5, 1-14, 58.

14. Gui-lan, L.; Wei-ya, X. Application of fuzzy Markov chains model in landslide stability prediction. Chin. J. Geol. Hazard. Control. 2006, 4, 14.

15. Xu, X.; Shang, Y.; Wang, Y. Research on comprehensive evaluation decision system for landslide disaster. Rock Soil Mech. 2010, 10, 22.

16. Huo, Z.; Liang, S. Application of Fuzzy Mathematics Method on Landslide Stability Assessment. Northwest. Seismol. J. 2007, 1, 35-39.

17. Ercanoglu, M.; Gokceoglu, C. Use of fuzzy relations to produce landslide susceptibility map of a landslide prone area (West Black Sea Region, Turkey). Eng. Geol. 2004, 75, 229-250. [CrossRef]

18. Tongzhen, Y. Prediction on Stages of Single Process Circle for Landslide and Ground Subsidence. Chin. J. Geol. Hazard. Control. 1990, 2, 11-21.

19. Li, C.; Tang, H.; Hu, X.; Li, D.; Hu, B. Landslide prediction based on wavelet analysis and cusp catastrophe. J. Earth Sci. 2009, 20, 971. [CrossRef]

20. Ren, D.; Leslie, L.M.; Fu, R.; Dickinson, R.E.; Xin, X. A storm-triggered landslide monitoring and prediction system: Formulation and case study. Earth Interact. 2010, 14, 1-24. [CrossRef]

21. Clare, M.A.; Talling, P.J.; Challenor, P.; Malgesini, G.; Hunt, J. Distal turbidites reveal a common distribution for large $\left(>0.1 \mathrm{~km}^{3}\right)$ submarine landslide recurrence. Geology 2014, 42, 263-266. [CrossRef]

22. Dietrich, W.E.; Bellugi, D.; De Asua, R.R. Validation of the shallow landslide model, SHALSTAB, for forest management. Water Sci. Appl. 2001, 2, 195-227.

23. Pope, E.L.; Talling, P.J.; Urlaub, M.; Hunt, J.E.; Clare, M.A.; Challenor, P. Are large submarine landslides temporally random or do uncertainties in available age constraints make it impossible to tell. Mar. Geol. 2015, 369, 19-33. [CrossRef]

24. Qiang, X.U. Understanding the Landslide Monitoring and Early Warning: Consideration to Practical Issues. J. Eng. Geol. 2020, 28, 360-374.

25. Liu, L.; Jiang, L.; Sun, Y.; Wang, H.; Sun, Y.; Xu, H. Diurnal fluctuations of glacier surface velocity observed with terrestrial radar interferometry at Laohugou No. 12 Glacier, western Qilian mountains, China. J. Glaciol. 2019, 65, 239-248. [CrossRef]

26. Shouren, Z. Major technical problems about river closure and second stage cofferdam design at Three Gorges Project. Yangtze River 1997, 4, 129-138.

27. Rödelsperger, S.; Läufer, G.; Gerstenecker, C.; Becker, M. Monitoring of displacements with ground-based microwave interferometry: IBIS-S and IBIS-L. J. Appl. Geod. 2010, 4, 41-54. [CrossRef]

28. Zhang, Y.; Luo, L.; Yang, J.; Liu, D.; Kong, R.; Feng, Y. A hybrid ARIMA-SVR approach for forecasting emergency patient flow. J. Ambient Intell. Human Comput. 2019, 10, 3315-3323. [CrossRef]

29. Shang-qing, W.; Jin-jun, X.U.; Mian, L. Study of warning of dangerous state of Baishuihe Landslide in Three Gorges Reservoir Area. J. Geomat. Inf. Sci. Wuhan Univ. 2009, 34, 1218-1221. 
30. He, K.; Chen, W.; Zhang, P. Real-time monitoring of dynamic stability coefficient and displacement criterion of the creep slope. J. Chin. J. Rock Mech. Eng. 2016, 35, 1377-1385.

31. Qiang, X.U.; Dalei, P.; Chaoyhang, H.; Xing, Q.; Kuanyao, Z.; Dehao, X. Theory and method of monitoring and early warning for sudden loess landslide-a case study at HeiFangTai Terrace. J. Eng. Geol. 2020, 28, 111-121.

(c)

(C) 2020 by the authors. Licensee MDPI, Basel, Switzerland. This article is an open access article distributed under the terms and conditions of the Creative Commons Attribution (CC BY) license (http://creativecommons.org/licenses/by/4.0/). 